\title{
Postpartum sterilization: a five years retrospective study
}

\author{
Mohana Dhanapal*, Kotteeswari Palanisamy Sivanandan, \\ Eswari Sengottian, Praveena Murugesan
}

Department of Obstetrics and Gynecology, Government Mohan Kumaramangalam Medical College, Tamil Nadu, India

Received: 01 May 2018

Accepted: 29 May 2018

\section{*Correspondence:}

Dr. Mohana Dhanapal,

E-mail: doctormohana@gmail.com

Copyright: (C) the author(s), publisher and licensee Medip Academy. This is an open-access article distributed under the terms of the Creative Commons Attribution Non-Commercial License, which permits unrestricted non-commercial use, distribution, and reproduction in any medium, provided the original work is properly cited.

\begin{abstract}
Background: Female sterilization, which is also called tubal ligation or tubal occlusion, is a surgical procedure which aims at permanent contraception. When female sterilization is performed at the time of birth with caesarean delivery or very soon after vaginal birth, such sterilization is called puerperal or postpartum sterilization. This study is to analyse the puerperal sterilization done in our hospital regarding age, living children, timing of sterilization and complications.

Methods: A retrospective analytical study of 6069 cases of puerperal sterilization performed over a period of 5 years from January 2013 to December 2017.

Results: During the study period, 6069 cases of puerperal sterilization cases were done. Out of which 4714 (77.67\%) patients had undergone caesarean tubectomy, 1355 (22.32\%) patients had undergone mini-laparotomy. Maximum number of patients was in the age group of 20-29yrs (80.3\%). Majority of patients $(68.62 \%)$ had two living children. Complications were encountered in $32.38 \%$ of patients.

Conclusions: The findings in this study showed that the incidence of voluntary surgical contraception is low. Adequate education and counseling will lead to acceptance of the procedure and consequently, a reduction in high maternal mortality from unwanted pregnancies.
\end{abstract}

Keywords: Caesarean tubectomy, Mini-laparotomy, Mesosalphinx tear

\section{INTRODUCTION}

Female sterilization, which is also called tubal ligation or tubal occlusion, is a surgical procedure, which aims at permanent contraception. When female sterilization is performed at the time of birth with caesarean delivery or very soon after vaginal birth, such sterilization is called puerperal or postpartum sterilization.

Female sterilization is usually chosen by those who have completed their family size. Tubal sterilization is also indicated for women in whom a pregnancy would pose a serious risk to the mother following multiple previous caesarean sections, repeat abruptions or serious cardiac, renal or hepatic conditions, or for reasons of grand multiparity.

The important feature of female sterilization is cost effective and require no subsequent follow up. Increased usage of contraception has direct effect on maternal deaths by reducing no. of pregnancies. ${ }^{1}$

Female sterilization is a relatively simple procedure that involves permanently blocking the fallopian tube to prevent fertilization. Female sterilization has important role to play in the reduction of high maternal mortality rate in the developing countries. Female sterilization is one of the most common forms of birth control 
worldwide being relied upon one in three women of reproductive age. ${ }^{2} 1 / 3^{\text {rd }}$ of pregnancy related deaths in the world could be prevented by the use of safe and effective family planning method. Hence to control the high maternal morbidity and mortality on one hand and the rapid population growth on the other. Provision of adequate health services with special emphasis on family planning is of paramount importance. ${ }^{3}$

\section{METHODS}

It is a retrospective analytical study carried out from January 2013 to December 2017 at Government Mohan Kumaramangalam Medical College and Hospital, Salem, Tamil Nadu, India. Total studied population were 6069 .

The case sheets of the study group were collected from MRD section and reviewed in detail regarding age, parity, number of living children, level of education, intraoperative and postoperative complications. The group were categorised into caesarean tubectomy and puerperal sterilization. All puerperal sterilization were done by mini laparotomy by Modified Pomeroy's Technique. Caesarean tubectomy was also done by Modified Pomeroy's Technique.

\section{Inclusion criteria}

Inclusion criteria were women who undergone sterilization during caesarean section; women who undergone sterilization following vaginal delivery within 7 days of postpartum period.

\section{Exclusion criteria}

Exclusion criteria were women who have undergone sterilization after 42 days of delivery; women who have undergone sterilization following an abortion, ectopic pregnancy and following menstruation.

\section{RESULTS}

Total no. of deliveries for the study period was 37435 , Of which 6069 had undergone sterilization. No. of high order births were 23108. 50 patients had undergone sterilization with one living child. Sterilization coverage for high order birth were only $26.04 \%$. In our study, a total of 6069 patients undergone postpartum sterilization. 1355 patients $(22.32 \%)$ were undergone postpartum sterilization, 4714 patients $(77.67 \%)$ were undergone caesarean tubectomy which showed in Table 1.

Table 2 shows the timings of tubectomy. In 2013, 24.31\% (282) patients underwent postpartum sterilization and $75.68 \%$ (878) patients underwent caesarean tubectomy. In the following years (2014-2017), postpartum sterilization were between 20.1 to $27.11 \%$, caesarean tubectomy were 72.88 to $79.99 \%$.

Table 1: Distribution of patients by sterilization methods.

\begin{tabular}{|lll|}
\hline Tubectomy methods & No.of patients & $\%$ \\
\hline Caesarean tubectomy & 4714 & 77.67 \\
\hline Postpartum sterilization & 1355 & 22.32 \\
\hline
\end{tabular}

Table 2: Total no. of patients who underwent sterilization by different methods in each year.

\begin{tabular}{|lllllll|}
\hline Year & Caesarean tubectomy & $\%$ & Minilap & $\%$ & Total & $\%$ \\
\hline 2013 & 878 & $75.68 \%$ & 282 & $24.31 \%$ & 1160 & $19.11 \%$ \\
\hline 2014 & 664 & $72.88 \%$ & 247 & $27.11 \%$ & 911 & $15.01 \%$ \\
\hline 2015 & 924 & $79.10 \%$ & 244 & $20.89 \%$ & 1168 & $19.24 \%$ \\
\hline 2016 & 1123 & $79.99 \%$ & 281 & $20.01 \%$ & 1404 & $23.13 \%$ \\
\hline 2017 & 1125 & $78.89 \%$ & 301 & $21.10 \%$ & 1426 & $23.49 \%$ \\
\hline
\end{tabular}

Table 3: Age distribution of patients undergone sterilization.

\begin{tabular}{|lll|}
\hline Age & No. of cases & $\%$ \\
\hline $20-24$ & 2292 & 37.76 \\
\hline $25-29$ & 2583 & 42.56 \\
\hline $30-34$ & 871 & 14.35 \\
\hline $35-39$ & 279 & 4.59 \\
\hline $40-44$ & 41 & 0.67 \\
\hline $45-49$ & 3 & 0.04 \\
\hline
\end{tabular}

Table 3 shows an age distribution of the patients. Maximum no. of patients (4875) $80.3 \%$ underwent sterilization between 20 -29 years. 1150 patients $(18.94 \%)$ were in the age group of $30-39$ years. 44 patients $(0.7 \%)$ were in the age group of more than 40 years. Regarding no. of living children, majority of patients $4165(68.62 \%)$ who underwent sterilization had two living children. 1576 $(25.96 \%)$ patients undergone sterilization had three living children. $278(4.58 \%)$ patients had four and above living children. $50(0.82 \%)$ patients had undergone sterilization with one living children. Considering the level of education, 3085 patients $(50.83 \%)$ who undergone sterilization had primary education. 1181 patients $(19.45 \%)$ had secondary education. 879 patients $(14.48 \%)$ had higher studies. 924 patients $(15.22 \%)$ had not attended their school at all. 
Table 4: Complications.

\begin{tabular}{|llll|}
\hline Complications & Caesarean tubectomy & Mini- laparotomy & Total\% of complications \\
\hline Difficulty in reaching the tubes & 0.84 & 0.34 & 1.18 \\
\hline Mesosalpinx tear and hematoma & 0.19 & 0.45 & 0.64 \\
\hline Febrile morbidity & 9.42 & 1.12 & 10.54 \\
\hline Paralytic ileus & 6.24 & 1.44 & 7.68 \\
\hline Wound infection & 7.51 & 1.10 & 8.61 \\
\hline Wound gaping & 6.10 & 0.29 & 6.39 \\
\hline CVT & 0.31 & - & 0.31 \\
\hline Death & 0.03 & - & 0.03 \\
\hline
\end{tabular}

Table 4 shows intraop and postop complications of tubectomy. It was encountered in $32.38 \%$ of patients. Of these, $0.64 \%$ had mesosalphinx tear and hematoma, $1.18 \%$ patients had difficulty in finding the tubes because of intraop adhesions. Of these, febrile morbidity were most common which contributes for $10.54 \%$ followed by paralytic ileus in $7.68 \%$, wound infection was $8.61 \%$, wound gaping was $6.39 \%$, CVT was encountered in $0.31 \%$ of patients, there was one death $(0.03 \%)$ due to sepsis. Of patients who had undergone sterilization between 2013-2017, 11 patients had sterilization failure. Out of these, 3 were ruptured ectopic pregnancy, 6 patients were presented for MTP with resterilization, 2 patients were continued the pregnancy.

\section{DISCUSSION}

The family planning is one of the pillar of reproductive health which is important for maternal and child health. The total number of high order birth were 23,108. Out of these, only $26.04 \%$ of high order births were covered by sterilization. The reason for the low acceptance rate of sterilization were fear of health risk thought to be associated with the procedure, religious factors, desire for the large family size, high infant and childhood mortality. Counselling of prospective clients for female sterilization actually starts at a clinics. Counsellor also talks antenatal health advice, diet advice, warning signs and family planning advice.

FIGO 2010 recommends to avoid female sterilization during caesarean section. But caesarean tubectomy is the preferred method of sterilization in developing countries. ${ }^{4}$ Postpartum tubal ligation is entirely elective. The only risk of delay is subsequent pregnancy. In a study by Thurman et al, women who requests of postpartum tubal ligation and fails to receive it become pregnant within one year at alarming rate of $47 \%$ vs $22 \%$ for those not requesting ligation. ${ }^{5}$ ACOG states, "Given the consequences of a missed procedure and the limited time frame in which it may be performed, postpartum sterilization should be considered urgent surgical procedure".

In our study out of 6069 patients, $77.67 \%$ of patients opted for caesarean tubectomy, $22.32 \%$ of patients underwent sterilization by postpartum mini-laparotomy. Whereas in study by Mutihir and Nyango who reported caesarean tubectomy was done in $15.9 \%$ of patients, Puerperal sterilization was done for $5.6 \%$ of patients. ${ }^{6}$ In a study by Swende et al, caesarean tubectomy was done in $47.4 \% .^{7}$ In an another study conducted in Brazil, caesarean tubectomy was done in $70 \%$ of patients. ${ }^{8}$

Maximum no. patients ( $80.3 \%$ ) underwent sterilization between 20-29 years which is similar to the study by Mahadevappa et al who reported $77.93 \%$ were in the age group of $20-29$ years. ${ }^{9} 94.58 \%$ ( $68.62 \%+25.96 \%$ ) of the patients who underwent sterilization had two or three living children, $0.82 \%$ of the patients had one living children. Whereas in a study by Kindan et al, the maximum number of patients were grand multi $(85.4 \%) .{ }^{10}$ Most of the patients studied upto primary education $(54.12 \%)$ and $23.46 \%$ of the patients had not educated at all.

All mini-laparotomy were done under spinal anaesthesia. The practice of female sterilization under local anaesthesia has almost disappeared from our centre. Previously $28.24 \%$ of cases done under i.v anaesthesia. But now for the past 2 years, we are doing all cases under spinal anaesthesia. For caesarean tubectomy, $99.10 \%$ were done under spinal anaesthesia. Only $0.9 \%$ were done under GA because of medical complications in pregnancy.

The incidence of wound infection in our study was $8.71 \%$ whereas it was $5.5 \%$ in a study by Swende and Akinbuwa. ${ }^{11}$ In our hospital we do only postpartum sterilization by mini laparotomy not by laparoscopic sterilization. In a study by Huber et al, they compared postpartum laparoscopic sterilization, Interval laparoscopic sterilization and postpartum Mini laparotomy. They reported major complications was higher in postpartum Mini laparotomy $(0.39 \%)$, minor complications like wound infection, UTI were $0.82 \%$. Major complications were blood loss of $>500 \mathrm{ml}$, febrile morbidity. Minor complications like wound infection, UTI were more in postpartum Mini laparotomy. ${ }^{12}$ In a study by Mule et al who also reported $84.6 \%$ of complications were of mini-laparotomy whereas in laparoscopic tubal ligation, complications were only $13.4 \% .^{13}$ Wang et al demonstrated that interval and 
postpartum laparoscopic sterilization is a safe, simple and quick operation and appears to be superior to postpartum minilaparotomy in terms of complications. ${ }^{14}$

\section{CONCLUSION}

The findings in this study showed that the incidence of voluntary surgical contraception is low. Among the reasons advanced for this low acceptance rate of sterilization are misconceptions, fears of a variety of health risk thought to be associated with the procedure. Other limitations include cultural and religious factors, great desire for a large family size. Adequate education and counseling will lead to acceptance of the procedure and consequently, a reduction in high maternal mortality from unwanted pregnancies. Health workers are efficient sources of information about the procedure. Thus, utilization of health education and mobilization programs will greatly improve acceptance and clear any myths and fears about the procedure.

Funding: No funding sources

Conflict of interest: None declared

Ethical approval: The study was approved by the Institutional Ethics Committee

\section{REFERENCES}

1. Royston E, Amstrong S. Preventing Maternal deaths. World Health Organisation, Geneva;1989:1-15.

2. Chandra A, Martinez GM, Mosher WD, Abma JC, Jones J. Fertility, Family planning and reproductive health of U.S Women: data from the 2002 National Survey of Family Growth. Vital Health Stat 23. 2005;(25):1-160.

3. Reich. J. The International Conference on Better Health FW Women and Children Through Family Planning. Int Fam Plann Presp. 1987;13:86-9.

4. Dickens B. Female Contraceptive Sterilisation: International Federation of Gynaecology and Obstetrics (FIGO) Committee for the Ethical Aspects of human reproduction and women's health. Int $\mathbf{J}$ Gynaecol obstet. 2011;115:88-9.

5. Thurman AR, Janecek T. One-year follow up of women with unfulfilled postpartum sterilization requests. Obstet Gynaecol. 2010;116:1071-7

6. Mutihir JT, Nyango DD. Quarter of a century of female sterilization in Jos, Central Nigeria. Afr J Reprod Health. 2011;15(1):101-6.

7. Swende TZ, Hwande TS. Female sterilization by tubal ligation at caesarean section in Makurdi, Nigeria. Ann Afr Med.2010;9(4):246-50.

8. Soares LC, Brollo JLA, Family planning in Brazil: why not tubal sterilisation during childbirth? J Med Ethics. 2013;39:710-2.

9. Mahadevappa K, Prasanna N, Channabasappa RA. Trends of various techniques of Tubectomy: A Five year Study in a Tertiary Institute. J Clin Diagn Res. 2016;10(1):QC04-7.

10. Kindan KG, Azeze B, Ismail S. Female Sterilization Through Mini-Laparotomy at Gondal College Medical Science. East Afr Med J. 2001;78(8):414-7.

11. Swende T, Akinbuwa B. Mini laparotomy Female Sterilisation At A Nigerian Tertiary Health Centre. The Internet J Gynaecol Obstet. 2009;13(1):1-6.

12. Huber AW, Mueller MD, Ghezzi F, Cromi A, Dreher E, Raio L. Tubal Sterilization: Complications of Laparoscopy and Mini Laparotomy. Eur J Obstet Gynecol Reprod Biol. 2007;134(1):105-9.

13. Mule VD, Date SV, Gadekar MS. Complications of female sterilization procedure: review over a decade at district tertiary care hospital. Int $\mathrm{J}$ Reprod Contracept Obstet Gynecol 2017;6:4309-13.

14. Wang PH, Lee WL, Yuan CC, Chin TW. Post Partum Sterilization: The choice of Laparoscopy or Minilaparotomy? Eur J Obstet Gynecol Reprod Biol. 2008;139(1):116-7.

Cite this article as: Dhanapal M, Sivanandan KP, Sengottian E, Murugesan P. Postpartum sterilization: a five years retrospective study. Int J Reprod Contracept Obstet Gynecol 2018;7:2878-81. 